\title{
Comparative Study of Ancient and Modern Japanese Swords using Neutron Tomography
}

\author{
Yoshihiro Matsumoto ${ }^{1, a^{*}}$, Kenichi Watanabe ${ }^{2, b}$, Kazuma Ohmae ${ }^{2, c}$, \\ Akira Uritani $^{2, \mathrm{~d}}$, Yoshiaki Kiyanagi ${ }^{2, \mathrm{e}}$, Hirotaka Sato ${ }^{3, \mathrm{f}}$, Masato Ohnuma ${ }^{3, \mathrm{~g}}$, \\ Anh Hoang Pham ', ', Shigekazu Morito ${ }^{4, i}$, Takuya Ohba '4,j, Kenichi Oikawa ${ }^{5, k}$, \\ Takenao Shinohara ${ }^{5,1}$, Tetsuya Kai ${ }^{5, m}$ Stefanus Harjo ${ }^{5, \mathrm{n}}$ and Masakazu Ito ${ }^{6,0}$ \\ ${ }^{1}$ Comprehensive Research Organization for Science and Society, Ibaraki 319-1106, Japan \\ ${ }^{2}$ Graduate School of Engineering, Nagoya University, Aichi, 464-8603, Japan \\ ${ }^{3}$ Faculty of Engineering, Hokkaido University, Hokkaido 060-8628, Japan \\ ${ }^{4}$ Interdisciplinary Faculty of Science and Engineering, Shimane University, Shimane 690-8504, \\ Japan \\ ${ }^{5}$ J-PARC Center, Japan Atomic Energy Agency, Ibaraki, 319-1195, Japan \\ ${ }^{6}$ WAKOU MUSEUM, Shimane 692-0011, Japan \\ ay_matsumoto@cross.or.jp, bk-watanabe@energy.nagoya-u.ac.jp, \\ coomae.kazuma@f.mbox.nagoya-u.ac.jp, ${ }^{d} u$ uritani@energy.nagoya-u.ac.jp,

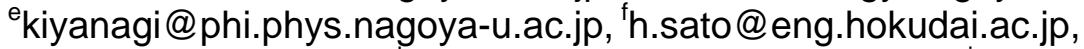 \\ gohnuma.masato@eng.hokudai.ac.jp, " $a n h p h a m @$ riko.shimane-u.ac.jp, 'imosh@riko.shimane- \\ u.ac.jp, ${ }^{j}$ ohba@riko.shimane-u.ac.jp, ${ }^{k}$ kenichi.oikawa@j-parc.jp, 'takenao.shinohara@j-parc.jp, \\ mtetsuya.kai@j-parc.jp, ${ }^{n}$ stefanus.harjo@j-parc.jp, ${ }^{0}$ masakazu_itoh@cup.ocn.ne.jp
}

Keywords: Japanese Sword, Neutron Tomography, RADEN

Abstract. We have performed neutron tomography using two ancient Japanese swords (designated Morikage and Sukemasa) and one modern Japanese sword (Masamitsu) at RADEN in the J-PARC Materials and Life Science Experimental Facility. For the ancient Japanese sword Morikage, it is found that the martensite iron is distributed in the region of about $3 \mathrm{~mm}$ from the cutting-edge and the ferrite iron is distributed in the inner region of the blade. The martensite iron area surrounds the inner ferrite iron area. For the ancient Japanese sword Sukemasa, the martensite iron is distributed only in a very narrow region at the cutting-edge and the homogeneous ferrite iron area is dominantly distributed in the inner region of the blade. In contrast to the ancient Japanese swords, the distribution of the martensite iron is about $8 \mathrm{~mm}$ from the cutting-edge and is similar to the wave pattern visible on the blade surface for the modern Japanese sword Masamitsu. Additionally for Masamitsu, a region where the neutron transmittance slightly increases was found at the interface between the martensite area and inner ferrite iron area. Line-like structures due to inclusions produced in the manufacturing process were also found in the blade. These results indicate that the manufacturing processes and raw materials of the Japanese swords are significantly different depending on the era and place of manufacture. Going forward, it is necessary to compare systematically the internal structure of more samples in order to clarify historical changes in Japanese sword making, and the nondestructive approach using neutron tomography is one of the powerful tools to elucidate them. 


\section{Introduction}

Japanese swords have superior characteristics in strength and toughness, giving them important value not only as historical works of art but also from a metallurgical point of view $[1,2]$. It is known that Japanese swords differ in the raw materials and manufacturing processes depending on the era and place of manufacture. Most modern Japanese swords use a special steel called Tamahagane that is smelted from iron sand and charcoal in the traditional steel-making system Tatara as the raw materials, and they are produced based on the manufacturing processes developed after the Edo period (17th - 19th century). On the other hand, with regard to ancient Japanese swords manufactured from the Kamakura period to the Muromachi period (12th - 16th century), there are still many unknown points both in the manufacturing processes and raw materials used due to lack of historical records. Comparing ancient Japanese swords with modern Japanese swords from the viewpoint of materials science can provide an important foothold for understanding the historical changes of the Japanese sword. In fact, investigations on Japanese swords have been conducted using various methods and valuable knowledge has been obtained [3-6]. Therefore, based on the above background, we have investigated the three-

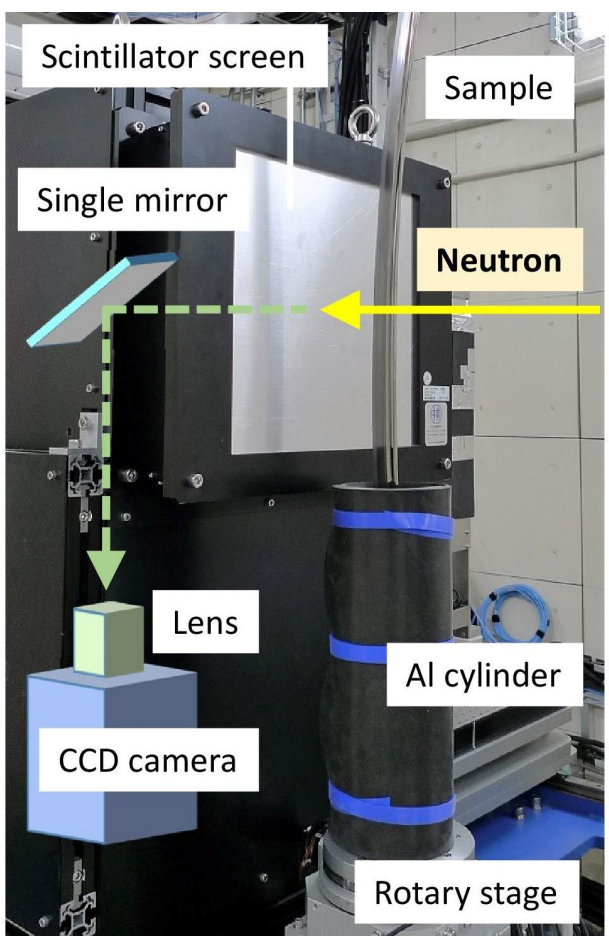

Fig. 1. Illustraion of the experimental setups of neutron tomography. dimensional internal structure and crystallographic structure of ancient and modern Japanese swords non-destructively using neutron tomography and Bragg-edge transmission (BET) imaging [7]. In this paper, we report the results of the neutron tomography measurement.

\section{Experimental}

Characteristics of the Japanese swords used in the present study are listed in Table 1. Morikage was manufactured in the Bizen district, the location of one of the five major sword schools, or "Gokaden", in the early Muromachi period. Sukemasa was manufactured in the Izumi district during the late Muromachi period. These swords are categorized as the ancient Japanese sword, or "Koto". Masamitsu was manufactured in Fukuoka prefecture in A.D. 1969 and is categorized to the modern Japanese sword, or "Gendaito".

Neutron tomography measurements were carried out at the pulsed neutron imaging instrument RADEN located at BL22 of the J-PARC Materials and Life Science Experimental Facility (MLF) [8]. The layout of the detection system used in the present study is illustrated in Fig. 1. This system consists of a camera-type detector and a rotary stage. Neutrons which penetrate the sample are converted to green light by the ${ }^{6} \mathrm{LiF}+\mathrm{ZnS}$ scintillator screen (RC Tritec Ltd.) of area $300 \times 300 \mathrm{~mm}^{2}$ and $0.1 \mathrm{~mm}$ thickness and focused on the camera sensor by a single mirror. In the present study, we adopted a large area CCD camera, the ANDOR iKon-L (Andor Technology Ltd.). This CCD camera provides 16 bit images, and its sensor $(2048 \times 2048$ active pixels) is cooled to $-100{ }^{\circ} \mathrm{C}$ with a Peltier module and coolant circulation to suppress dark current noise. These components are installed in the detector box covered with thin black aluminum plates, thick lead plates and boron rubber sheets to reduce undesirable noise due to scattered neutrons, $\gamma$-ray irradiation and light leaks. Each Japanese sword was adequately 
protected so as not to destroy its cultural and artistic values, and then held vertically in the aluminum cylinder mounted on the rotary stage as shown in Figure 1. This aluminum cylinder was covered with boron rubber sheets to avoid activation of the sample outside the neutron irradiation area. As for neutron tomography measurements, both the camera-type detector and the rotary stage can be controlled simultaneously using the device control software framework IROHA2 of J-PARC MLF [9]. J-PARC consists of the multi-purpose facilities, and neutron intensity changes during data acquisition due to accelerator trips, proton beam sharing and so on. Thus, the transmission image data is saved and the rotary stage turns to the next condition only when the number of proton pulses injected to the neutron target satisfies a set point estimated from the camera exposure time. In this way, a projection image that is not influenced by fluctuation of the pulsed neutron source can be acquired automatically. Each projection image was normalized by the neutron beam intensity after subtracting dark current noise. The computed reconstruction of the two-dimensional images (tomograms) of the sample by the filtered-backprojection method was performed using the visualization software VG studio MAX (Volume Graphics $\mathrm{GmbH}$ ). All projection images were measured with a field of view of $150 \times 150 \mathrm{~mm}^{2}$, L/D of 400 and camera exposure time of $100 \mathrm{sec}$ using a white neutron beam. As the proton beam power in the present study was about $150 \mathrm{~kW}$, neutron fluence per projection would be about $2.9 \times 10^{8} \mathrm{n} / \mathrm{cm}^{2}$ as estimated from the time-averaged neutron flux of $5.8 \times 10^{7}$ $\mathrm{n} / \mathrm{sec} / \mathrm{cm}^{2} / \mathrm{MW}$ expected from the design parameters of RADEN [7]. Distance from the rotational center of the sample to the scintillator screen was set to $70 \mathrm{~mm}$, giving a geometric blurring of approximately $0.18 \mathrm{~mm}$ at the scintillator screen.

\section{Result and Discussion}

Fig. 2 shows the tomograms from around the middle area of the swords. The XZ-plane and the $\mathrm{XY}$-plane correspond to a parallel plane and a perpendicular plane with respect to the longitudinal direction of the blade. The projection images used for the reconstruction were obtained by rotating the sample from $-180^{\circ}$ to $+180^{\circ}$ by $1^{\circ}$ steps for Morikage and Masamitsu and from $0^{\circ}$ to $171^{\circ}$ by $1^{\circ}$ steps for Sukemasa, respectively. Since we had to reduce the number of the projection images significantly from the usual value of 500-800 [10] due to the limited available measurement time and an unexpected neutron beam stoppage, the spatial resolution for this neutron tomography should be less than $0.5 \mathrm{~mm}$ judging from our previous study [11]. As for Morikage, it is found that there is a difference in the grayscale between the region of about $3 \mathrm{~mm}$ from the cutting-edge and the inner region of the blade in the XZ-plane tomogram. It is known that the martensite iron formed by quench hardening is distributed near the cutting-edge and ferrite iron is distributed in the inner region of the blade depending on the manufacturing processes of the swords [2,5]. Since the similar crystallographic structure was also obtained from our BET imaging measurement conducted to Morikage, the observed difference is thought to correlate with the distribution of the martensite and ferrite irons. From the XY-plane tomograms, it can be seen that the martensite iron area surrounds the ferrite iron area. The concave structures appearing on both sides of the blade are cutting structures for achieving weight reduction and improved rigidity of the sword, and they reach into the ferrite iron area. In contrast, the difference in the grayscale is only barely visible near the cutting-edge in both the XZ-plane and $\mathrm{XY}$-plane tomograms for Sukemasa. The grayscale in the inner region of the blade is nearly constant, so it is considered that the homogeneous ferrite iron is dominant in this region. From the BET imaging measurement [12], the crystallite size distribution is considerably uniform except in a very narrow region from the cutting-edge. The manufacturing processes and raw materials used for Morikage and Sukemasa seem to be different even though they were produced in the same Muromachi period. As for Masamitsu, the martensite iron is distributed near the cutting-edge, as in the ancient Japanese swords, judging from the XZ-plane and XY-plane 
tomograms, but its range is significantly different. The martensite iron appears to spread more than $8 \mathrm{~mm}$ from the cutting-edge, in agreement with the results of the BET imaging measurement [12], and its distribution closely resembles the wave-pattern visible on the blade surface, called the "Hamon". From this, it is considered that the quench hardening was done to the deep part of the blade to produce a sharp Hamon pattern. Furthermore, the grayscale of the interface between the martensite iron area and the inner ferrite iron area seems to be slightly darker, which means the neutron transmission is higher compared to the surrounding areas. At the present time, it is inferred that a component with small neutron cross section or low atomic density is distributed in the interface region, though a more detailed analysis is needed. On the other hand, bright line-like structures were found in the blade surrounded by the yellow circle especially from the XZ-plane tomogram. This is considered to be due to inclusions containing components having a large neutron cross section (for example, borax used in the forging process). Thus, the manufacturing processes, raw materials and residual materials of the modern Japanese sword Masamitsu are seen to be significantly different compared to the ancient Japanese swords. The grayscale contrast observed in the tomogram depends on not only the neutron absorption cross section but also the various factors such as neutron scattering, diffraction effects and so on. It will be necessary to investigate what kind of factors cause the contrast and feed back to the tomographic analysis of the Japanese sword.

(a) Morikage
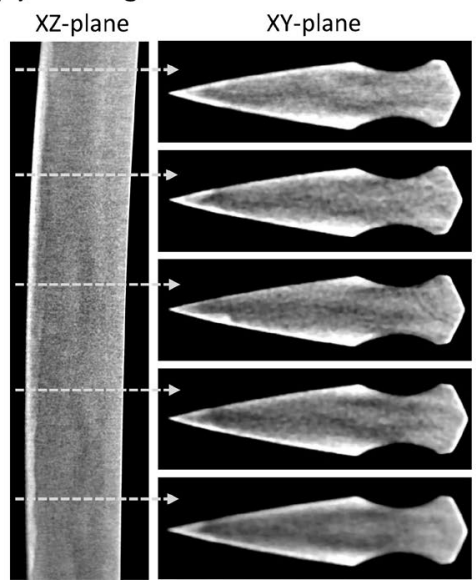

(b) Sukemasa

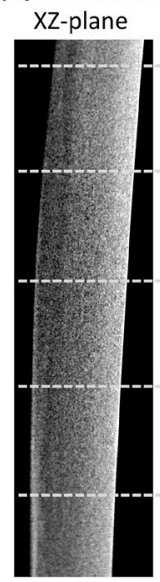

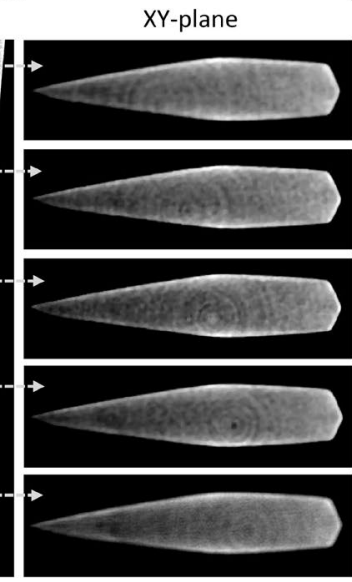

(c) Masamitsu

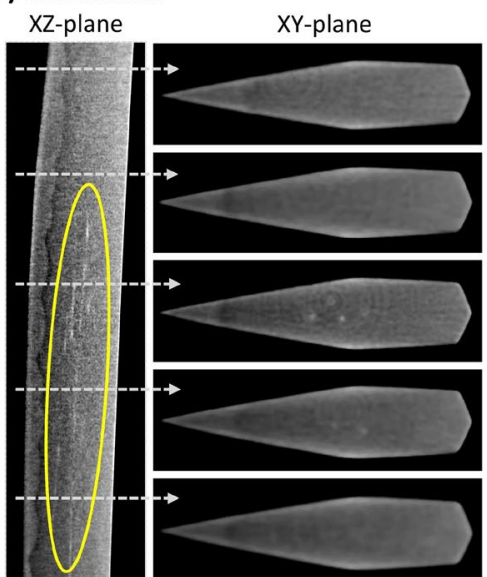

Fig. 2. The XZ-plane and XY-plane computed tomograms around the middle area of the blades of the ancient Japanese swords (a) Morikage and (b) Sukemasa and the modern Japanese sword (c) Masamitsu.

\section{Summary}

The three-dimensional internal structure of the ancient Japanese swords (Morikage and Sukemasa) and the modern Japanese sword (Masamitsu) were investigated non-destructively using neutron tomography. In both the ancient and modern Japanese swords, the martensite iron formed by quench hardening is distributed near the cutting-edge and the ferrite iron is distributed in the inner region of the blade. However, the range of the martensite iron is very different for each sword. In the case of the ancient Japanese swords, the martensite iron is distributed only to a few millimeters from the cutting-edge, while in the case of the modern Japanese sword, it extends to a wide area of about $8 \mathrm{~mm}$ from the cutting-edge. This should be due to the quench hardening treatment to the deep part of the modern blade done to produce the clear Hamon pattern. In addition, it is found that there are inclusions and residual materials that may be produced in the manufacturing processes of the modern Japanese sword, which cannot be confirmed with the ancient Japanese swords. We thus succeeded in obtaining some new 
knowledge about the manufacturing processes and raw materials of the Japanese swords. In the future, we will systematically investigate many samples covering different manufacturing eras and locations to clarify historical changes in Japanese sword making.

\section{Acknowledgement}

Neutron tomography experiments at the J-PARC MLF were performed under Proposal Nos. 2017A0099 and 2016B0163. This work partially includes the results of 'Collaborative Important Researches’ organized by JAEA, QST and U. Tokyo.

\section{References}

[1] M.R. Notis, The history of the metallographic study of the Japanese sword, Materials Characterization 45 (2000) 253-258. https://doi.org/10.1016/S1044-5803(01)00101-2

[2] T. Inoue, The Japanese sword; the material, manufacturing and computer simulation of quenching process, Materials Science Research International 3 (1997) 193-203. https://doi.org/10.2472/jsms.46.12Appendix_193

[3] F. Grazzi, L. Bartoli, F. Civita, A.M. Paradowska, A. Scherillo, M. Zoppi, Non destructive characterization of phase distribution and residual atrain/stress map of two ancient (Koto) age Japanese swords, Materials Science Forum 652 (2010) 167-173. https://doi.org/10.4028/www.scientific.net/MSF.652.167

[4] F. Grazzi, L. Bartoli, F. Civita, R. Franci, A. Paradowska, A. Scherillo, M. Zoppi, From Koto age to modern times: Quantitative characterization of Japanese swords with time of flight neutron diffraction, J. Anal. At. Spectrom. 26 (2011) 1030-1039. https://doi.org/10.1039/c0ja00238k

[5] M. Yaso, T. Takaiwa, Y. Minagi, T. Kanaizumi, K. Kubota, T. Hayashi, S. Morito, T. Ohba, Study of Japanese sword from a viewpoint of steel strength, J. Alloys Compd. 577 (2013) S690S694. https://doi.org/10.1016/j.jallcom.2012.06.141

[6] F. Salvemini, F. Grazzi, N. Kardjilov, I. Manke, F. Civita, M. Zoppi, Neutron computed laminography on ancient metal artefacts, Anal. Methods 7 (2015) 271-278. https://doi.org/10.1039/C4AY02014F

[7] Y. Kiyanagi, H. Sato, T. Kamiyama, T. Shinohara, A new imaging method using pulsed neutron sources for visualizing structural and dynamical information, J. Phys. Conf. Ser. (2012) 340 021010. https://doi.org/10.1088/1742-6596/340/1/012010

[8] T. Shinohara, T. Kai, K. Oikawa, M. Segawa, M. Harada, T. Nakatani, M. Ooi, K. Aizawa, H. Sato, T. Kamiyama, H. Yokota, T. Sera, K. Mochiki, Y. Kiyanagi, Final design of the EnergyResolved Neutron Imaging System "RADEN" at J-PARC, J. Phys. Conf. Ser. 746 (2016) 012007. https://doi.org/10.1088/1742-6596/746/1/012007

[9] T. Nakatani, Y. Imamura, T. Ito, T. Otomo, The control software framework of the web base, J. Phys. Conf. Ser. 8 (2015) 036013. https://doi.org/10.7566/JPSCP.8.036013

[10]A.C. Kak, M. Slaney, Principles of computerized tomographic imaging, Classics in Applied Mathematics, SIAM, Philadelphia, USA, 2001, pp. 49-112.

https://doi.org/10.1137/1.9780898719277

[11]Y. Matsumoto, M. Segawa, T. Kai, T. Shinohara, T. Nakatani, K. Oikawa, K. Hiroi, Y.H. Su, H. Hayashida, J.D. Parker, S.Y. Zhang, Y. Kiyanagi, Recent progress of radiography and 
tomography at the energy-resolved neutron imaging system RADEN, Phys. Procedia 88 (2017) 162-166. https://doi.org/10.1016/j.phpro.2017.06.022

[12] K. Oikawa, Y. Kiyanagi, H. Sato, K. Ohmae, A.H. Pham, K. Watanabe, Y. Matsumoto, T. Shinohara, T. Kai, S. Harjo, M. Ohnuma, S. Morito, T. Ohba, A. Uritani, M. Ito, Crystallographic structure study of a Japanese sword made by Sukemasa in the Muromachi period using pulsed neutron imaging, Mater. Res. Proc. (this proceedings)

[13] K. Ohmae, Y. Kiyanagi, H. Sato, K. Oikawa, A.H. Pham, K. Watanabe, Y. Matsumoto, T. Shinohara, T. Kai, S. Harjo, M. Ohnuma, S. Morito, T. Ohba, A. Uritani, M. Ito, Crystallographic structure study of a modern Japanese Masamistu using pulsed neutron imaging, Mater. Res. Proc. (these proceedings) 